\title{
Development and evaluation of a standardised means for estimating herbage mass of dairy pastures using the rising plate meter.
}

\author{
N.A. THOMSON ${ }^{1}$, M.P. UPSDELL ${ }^{2}$, R. HOOPER ${ }^{3}$, H.V. HENDERSON ${ }^{2}$, M.B. BLACKWELL $^{1}$, \\ D.A. MCCALLUM ${ }^{4}$, R.J. HAINSWORTH ${ }^{1}$, K.A. MACDONALD ${ }^{1}$, D.D. WILDERMOTH ${ }^{1}$, \\ G.J. BISHOP-HURLEY ${ }^{5}$ and J.W. PENNO' ${ }^{1}$. \\ ${ }^{1}$ Dexcel, Private Bag 3123 Hamilton \\ ${ }^{2}$ AgResearch Ruakura, Private Bag 3123, Hamilton \\ ${ }^{3}$ Auckland University, Auckland \\ ${ }^{4}$ Rainee Rd, Manaia, Taranaki \\ ${ }^{5}$ Massey University, Palmerston North \\ 1norman.thomson@dexcel.co.nz
}

\begin{abstract}
Calibration data for the rising plate meter (RPM) collected from four locations and spanning a period of 10 years (1988-1998) were used to develop a pooled standard set of RPM calibrations to be used to estimate herbage mass of dairy pastures across a number of dairying regions. When evaluated in a farmlet study run over a 2-year period, the standard RPM calibration gave similar estimates of average farm cover, pre and postgrazing herbage mass and consumed DM, as herbage mass estimates calculated from RPM measurements calibrated to the local pasture on each assessment day. Compared with visual estimations, the standard RPM calibration underestimated pre-grazing herbage mass, average farm cover and the amount of pasture consumed, and overestimated post-grazing herbage mass. Reasons for these differences are discussed and an alternative approach to using the RPM for on-farm pasture assessment is presented. Standardised, onfarm herbage mass estimates may be possible using the RPM and standard calibrations to calibrate visual estimations prior to visually assessing pasture across the whole farm. Such a standardised pasture assessment method would assist the grazing management of dairy pastures across a number of New Zealand dairying districts.
\end{abstract}

Keywords: average farm cover, dairy-grazing management, pasture growth, post-grazing herbage mass, pre-grazing herbage mass, rising plate meter

\section{Introduction}

The New Zealand dairy industry is dependent on pasture to feed dairy cows. How much pasture grows, and when it grows is what drives the industry. Despite the importance of pasture, minimal attention has been given to developing standard, easy to adopt, accurate pasture assessment methods. A variety of methods are available but for each method, a range of calibrations has been developed to convert instrument reading to herbage mass. This resulted in a range of recommendations for target average farm covers, and pre- and post-grazing herbage mass levels being reported (Thomson et al. 1997). For greater adoption of well-researched grazing management practices these authors stressed the need for greater standardisation of pasture assessment techniques.

Many of the calibrations commonly used to convert instrument reading to herbage mass, remain constant throughout the year, despite seasonal variation in pasture morphology influencing height/mass, density/ mass, and capacitance/mass relationships. L'Huillier \& Thomson (1988) reported that instrument reading/ herbage mass relationships varied between seasons and the variation was consistent between locations and between years. From a lack of a regional effect, these authors pooled the data and reported relationships between herbage mass and RPM readings on a seasonal basis. These calibrations changed on calendar date and resulted in considerable shifts in estimates of herbage mass with change of calibration. The size of these changes caused confusion for the practitioner and led to poor adoption of the standardised seasonal equations.

All calibrations for the RPM will give an indication whether pre-set targets for a particular farm are being achieved but the information may not be transferable to different dairying systems in different regions. Also, many of the reported target herbage mass levels were not comparable to recommendations from research institutions (Thomson et al. 1997).

From the time L'Huillier \& Thomson (1988) published their results, many additional sets of RPM calibrations were available from different dairy research institutions. These were obtained and a revised standardised method for calibrating the RPM was developed. Data from weekly pasture assessments for 
individual paddock RPM readings, individual paddock visual estimates and weekly calibration data for RPM and visual assessments were also available from the Dexcel No 2 Dairy farm systems research unit. These data were used to evaluate the revised standardised RPM calibrations. The aims of the programme were:

- Determine regional and farm effects on RPM and herbage mass relationships.

- Develop a robust set of relationships that could be used in association with the RPM over a range of dairy farms in different dairying regions of New Zealand.

- Test these relationships on an experimental dairy farm in which weekly calibrated RPM estimates of herbage mass were available.

\section{Methods}

Data collection for standardised RPM calibration RPM calibration data was collected from Massey University farms (Manawatu), WestpacTrust Agricultural Research Station (WTARS (South Taranaki)) and Dexcel's No 2 and No 5 Dairies (Waikato) that covered the period 1988-1998. The duration of each study and sample numbers undertaken at each site to establish calibrations is summarised in Table 1. Average annual rainfall was $1200 \mathrm{~mm} /$ year for Massey University and Dexcel farms, and $1050 \mathrm{~mm} /$ year for WTARS. At the three sites, a soil moisture deficit during summer was considered a restriction to pasture growth and dairy production. The dominant pasture species at each location were perennial ryegrass $(60$ $80 \%)$ and white clover $(5-20 \%)$. The presence and proportion of other pasture species differed between regions. At Massey University the other species category was dominated by Poa species, at WTARS by $P o a$ species and cocksfoot, and at Dexcel, by Poa species and annual summer grasses. The methods adopted for collecting the paired RPM readings and herbage mass measurements (the total amount of pasture above ground level, expressed as $\mathrm{kg} \mathrm{DM} / \mathrm{ha}$ ) have been reported elsewhere: for Massey University (Bishop-Hurley et al. 1997), WTARS (Thomson et al. 1997) and Dexcel, (Lile et al. 2001). In summary, RPM readings and herbage mass were collected from $0.2-0.3 \mathrm{~m}^{2}$ quadrats (the number of quadrants cut per calibration are summarised in Table 1). Two to four RPM readings per quadrat were recorded and the pasture cut to ground level using either a sheep shearing hand piece or electric clippers fitted with sheep shearing combs and cutters. All cut herbage was removed, washed to remove soil and faecal material and dried at $90^{\circ} \mathrm{C}$ to constant weight (usually 48 hours). At WTARS and Dexcel Farms, paired measurements (RPM reading and herbage mass) were taken from within the calibration quadrat but at Massey University the paddock was the individual unit or quadrat. For this calibration, an average RPM reading for a paddock was determined then five randomly placed quadrats were cut to determine the average herbage mass in the paddock. At all sites, the Ashgrove ${ }^{\mathrm{TM}}$ RPM was used.

\section{Calibration formulation}

For each of the 327 regressions of RPM reading on herbage mass, regression coefficients (slope) and intercepts were obtained. These relationships varied during any year at the four locations in a predictable manner. Considering this, a novel approach to managing curvilinear data, flexi plot" (Upsdell 1994), was adopted. The intercepts at $50 \mathrm{~mm}$ compressed height (RPM reading 10) were used rather than those at zero to reduce the bias caused by the lack of independence between slope and intercept of any single regression equation. These estimates, together with their standard errors and time of measurement, formed the data for the seasonal estimation of the calibration equations. The slope and intercept estimates were smoothed using a mixed model smoother, "flexi plot" (Upsdell 1994).

The model used was:

Table 1 Duration of study, number of calibrations (1), and number of paired observations (2) (rising plate meter reading and herbage mass) at each location.

\begin{tabular}{|c|c|c|c|c|c|c|c|c|c|c|c|}
\hline & & 1983 & 1984 & 1985 & 1986 & 1987 & 1992 & 1993 & 1994 & 1995 & 1996 \\
\hline \multirow[t]{2}{*}{ Massey } & 1 & - & - & - & - & - & - & 4 & 19 & 19 & 8 \\
\hline & 2 & - & - & - & - & - & - & 15 & 11 & 12 & 11 \\
\hline \multirow[t]{2}{*}{ WTARS } & 1 & 45 & - & 47 & - & - & 11 & 30 & - & 27 & - \\
\hline & 2 & 7 & - & 7 & - & - & 12 & 12 & - & 12 & - \\
\hline Dexcel \#2 1 & - & - & - & - & - & 45 & 15 & - & - & - & - \\
\hline \multirow[t]{2}{*}{ Dexcel \#5 1} & - & - & 8 & 20 & 2 & - & - & - & - & - & - \\
\hline & 2 & - & 15 & 14 & 15 & - & - & - & - & - & - \\
\hline
\end{tabular}


$\mathrm{Y}=\mathrm{C}+$ Seasonal curve + Day effect + Residual error Where

$\mathrm{Y}$ is the slope (and later the intercept).

$\mathrm{C} \quad$ is a constant

Seasonal curve is a curve constrained to have the same value at both ends of the year.

Day effect is a random effect allowing for conditions that only occur on the day of measurement, e.g., moisture content of air or grass.

Residual error is the error in determining Y. The standard errors of the slopes obtained with the slopes provide an estimate of their size.

A mixed model smoother works by the user specifying a functional form for the covariance between the estimates of the curve at different points rather than a functional form for the curve itself.

Standard errors of the slopes were used to specify the standard error of each residual error to ensure that regressions where the slopes were poorly estimated, often owing to a lack of spread in amount of herbage mass present, were down weighted. Then, by comparing daily means, we were able to establish if regional differences occurred. If no regional effects were apparent then all data were to be pooled and a standard RPM calibration established.

\section{Evaluation of the standard RPM calibration}

Weekly pasture assessment data using the RPM and visual assessments were made available from the farm systems study run at Dexcel No 2 Dairy (Macdonald et al. 2001). In this study five stocking rates, 2.2 to 4.3 cows/ha, were run under two management systems; one determined from years of grazing management research run on the No 2 Dairy and one determined by the simulation model UDDER (Larcombe 1989). In this study, calibrated weekly estimates of herbage mass from each paddock were determined using the Farm Works ${ }^{\mathrm{TM}}$ RPM and visually by at least two trained estimators from the low, medium, and high stocked farmlets from September 1998 to September 2000. The average RPM reading for each paddock was also used to calculate herbage mass using the standard RPM calibrations. For the 2-year period, the average farm cover determined by the No 2 weekly calibrated RPM (No 2 plate) and visual assessments of herbage mass were compared to herbage mass calculated using the standard RPM calibration (standard plate). Thomson (1985) reported the unreliability of the RPM to determine herbage mass at levels greater than $4000 \mathrm{~kg}$ $\mathrm{DM} / \mathrm{ha}$, as assessed visually. To minimise this bias, all paddocks with visual estimates of herbage mass greater than $4000 \mathrm{~kg} \mathrm{DM} / \mathrm{ha}$ were excluded from all comparisons of herbage mass estimations. To obtain an estimate of pre- and post-grazing herbage mass, the paddock visually assessed as having the highest herbage mass (excluding paddocks with greater than $4000 \mathrm{~kg}$ $\mathrm{DM} / \mathrm{ha}$ ) and the paddock visually assessed as having the lowest herbage mass were selected weekly as representative of the respective pre- and post-grazing herbage mass estimates.

\section{Results and discussion}

\section{Establishment of the standard calibration}

All weekly calibrations between RPM and herbage mass fitted a significant $(\mathrm{p}<0.01)$ linear regression. In more than $80 \%$ of the linear regression equations describing the RPM/herbage mass relationship, the herbage mass at zero RPM reading (the intercept) was significantly greater than zero. In the three regions, and for two farms in one region, the fitted seasonal curves and standard errors for slope and intercept established by "flexi plot" were similar and the daily average relationships for each location lay within the variance of the estimate. From this, the authors concluded at each location on any day, the relationship between RPM and herbage mass was similar. This allowed the data from the four locations to be pooled and a standard set of relationships established (Figure 1). These standard relationships will apply to any ryegrass/clover dairy pasture in environments similar to those encountered in Manawatu, South Taranaki and Central Waikato in which low summer rainfall is a limitation to pasture and dairy production.

The argument was put forward that a relationship between RPM and herbage mass that differed for each day of the year was too complicated and average seasonal relationships similar to those reported by L'Huillier \& Thomson (1988) should be established. This was done by Thomson \& Blackwell (1999) but the question arises with curvilinear data - when does an average seasonal equation actually apply? The authors believe, use of the specific slope and intercept presented in Figure 1 for the date the RPM readings were taken will overcome this problem and better adoption of standardised RPM herbage mass estimates should result.

Comparison of the standard RPM herbage mass calculations with on-site calibrated herbage mass estimates

Average farm cover

Differences between the three pasture assessment methods, standard plate, No 2 plate, and visual estimation were unaffected by stocking rate or farm 
Figure 1 Seasonal variation and standard error estimates of the pooled slope and intercept values for estimating herbage mass from compressed height as determined by the rising plate meter (RPM).

\section{Regression coefficient (slope)}

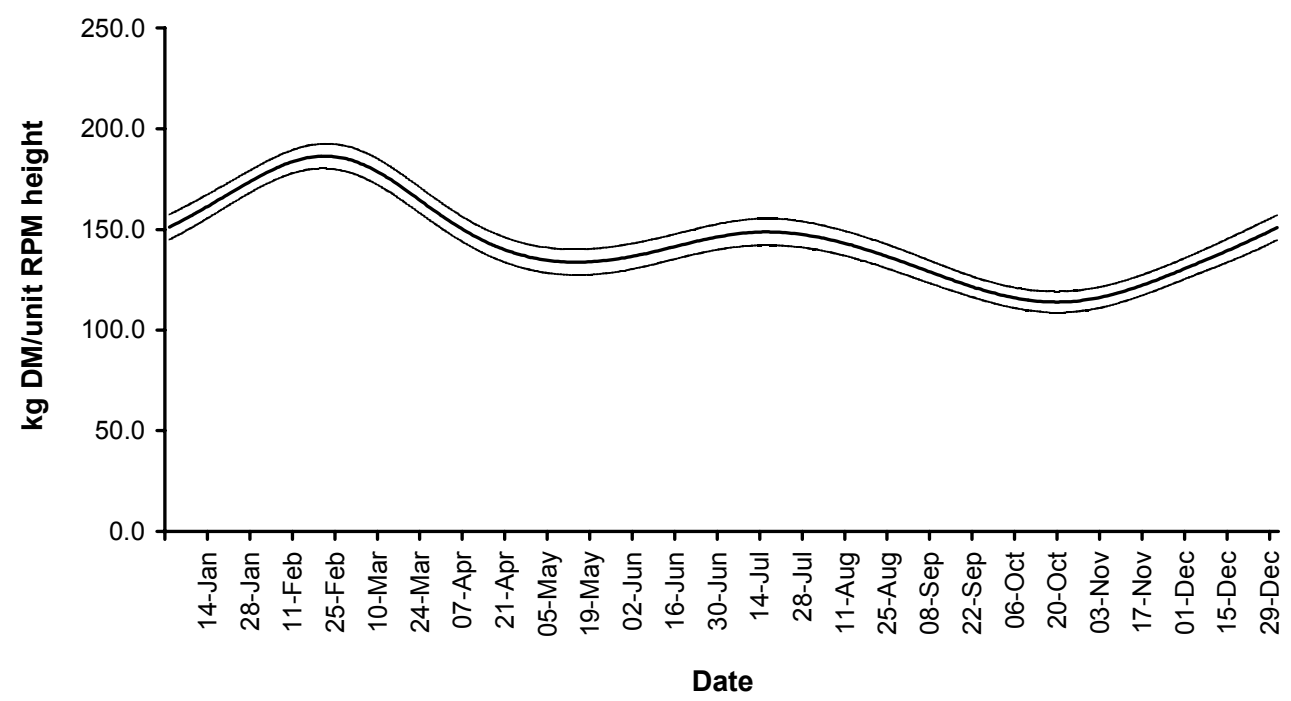

Intercept at RPM 10

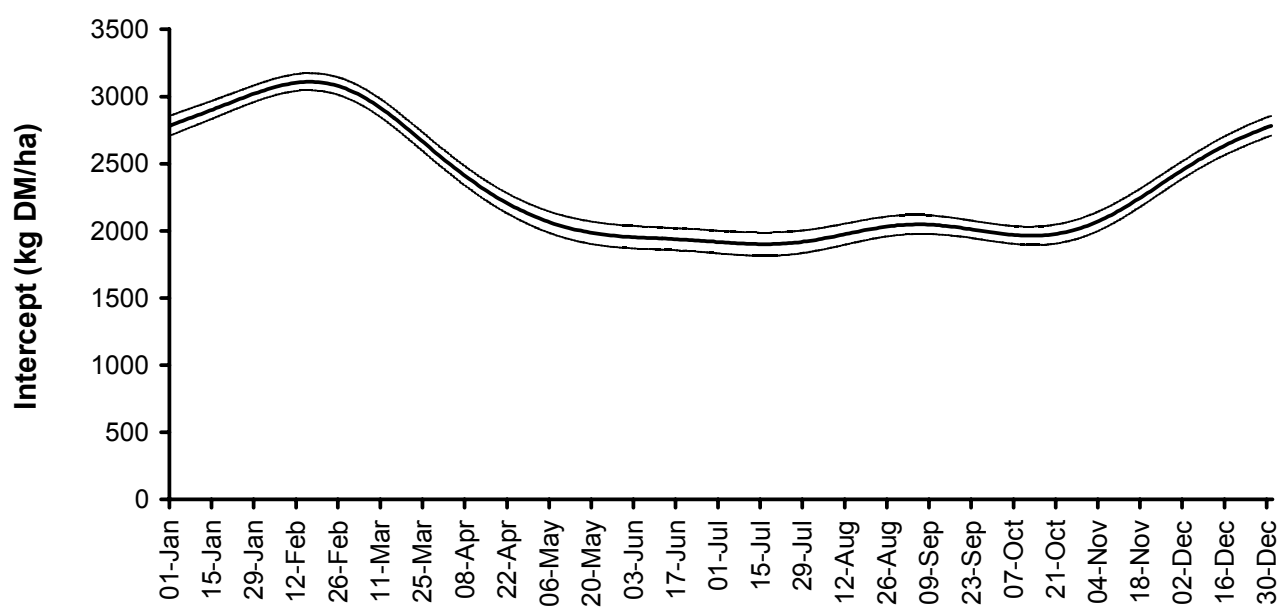

\section{Date}

management practice (Figure 2). This allowed comparisons of average farm cover to be made using data from all paddocks assessed in the study. For most of the comparison period, both methods gave similar values for herbage mass that varied in a similar manner throughout the study period. However, during winter 2000, the standard RPM calibration estimated a higher farm cover than the No 2 calibrated RPM reading.
This suggesting a change had occurred in either pasture composition, pasture morphology or in calibration procedures. Macdonald et el. (2001) reported no severe feed shortage in winter 2000 or lower than normal calving liveweight or body condition following that winter (Macdonald pers. comm.). The average RPM reading recorded during the period in question was similar to winter 1999 (9.1 versus 8.4; 1999 versus 
Figure $\llbracket 2$ Average farm cover recorded at Dexcel No 2 Dairy from September 1998 to September 2000 using a standard and on-farm calibration of the rising plate meter.

\section{Average farm cover}

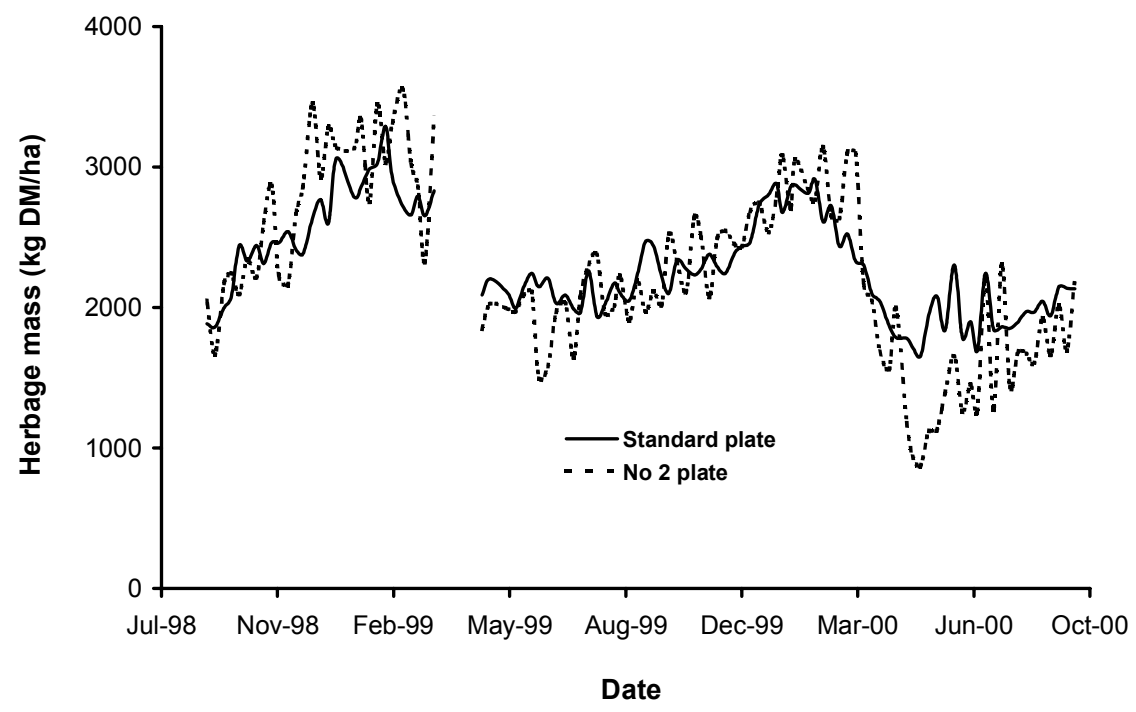

2000) suggesting only a slightly lower average farm cover.

Stockdale (1984) and L'Huillier \& Thomson (1987) noted consistency of the RPM/mass relationships during winter/early spring, which leads to the conclusion, the low herbage mass recorded for the No 2 calibrated RPM during winter 2000 was possibly owing to inconsistencies in calibration procedures. Excluding the information on herbage mass collected during winter 2000 , the conclusion is drawn that similar average farm covers were recorded using either the No 2 or the standard RPM calibration (Figure 2). Thomson et al. (1997) also concluded, for the assessment of average farm cover, a standard RPM calibration determined by L'Huillier \& Thomson (1987) was as suitable as a calibration determined for that farm on the day of assessment. Therefore, the RPM and standard calibrations would provide a standard method of measuring and comparing average farm covers on dairy farms.

Pre and post-grazing estimates of herbage mass The average estimates and seasonal variation of herbage mass pre- and post-grazing were similar for the standard and the No 2 plate methods of RPM calibration (Figure 3). The considerable deviation between the two methods recorded during winter 2000 has been previously discussed. In conclusion, the standard calibration and the No 2 calibration produced similar levels for herbage mass assessed either pre- or postgrazing. The two RPM calibration methods were tested under extreme pasture conditions; i.e., the highest herbage mass (pre-grazing) was probably selected from the low stocked farmlets and lowest herbage mass (post-grazing) from the high stocked farmlet. Considering that under these extremes the standard and the No 2 RPM calibrations gave similar estimates for average farm cover, and pre grazing and postgrazing herbage mass, it is concluded the standard RPM was as reliable at estimating herbage mass as an on-site calibrated RPM. This again indicates that greater standardisation of herbage mass estimates for ryegrass/ clover dairy pastures in the drier summer regions using the RPM will be possible.

\section{Comparison of the standard calibration with visual assessment}

Compared with standard calibrated RPM, visual assessment has for the 2 years of study, given higher pre-grazing herbage mass, higher average farm covers and similar to or lower, post-grazing herbage mass values (Table 2). These differences and similarities were consistent throughout the measurement period (Figure 4). Which of the herbage mass estimates was correct cannot be determined because the actual herbage mass in a paddock was not measured. Lile et al. (2001) concluded the visual estimate was more realistic because the resulting pasture parameters related better 
Figure $₫ 3$ Pre- and post-grazing herbage mass recorded at Dexcel № 2 Dairy from September 1998 to September 2000 using a standard and on-farm calibration of the rising plate meter.

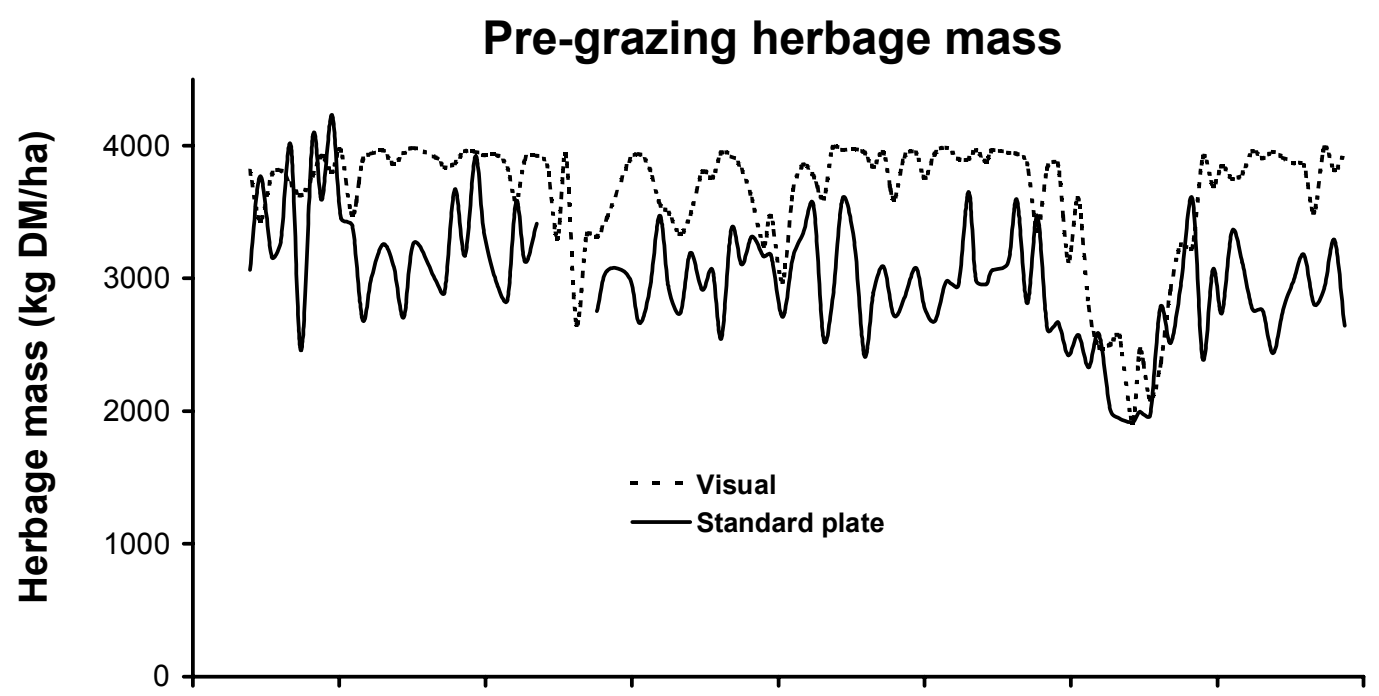

\section{Post- grazing herbage mass}

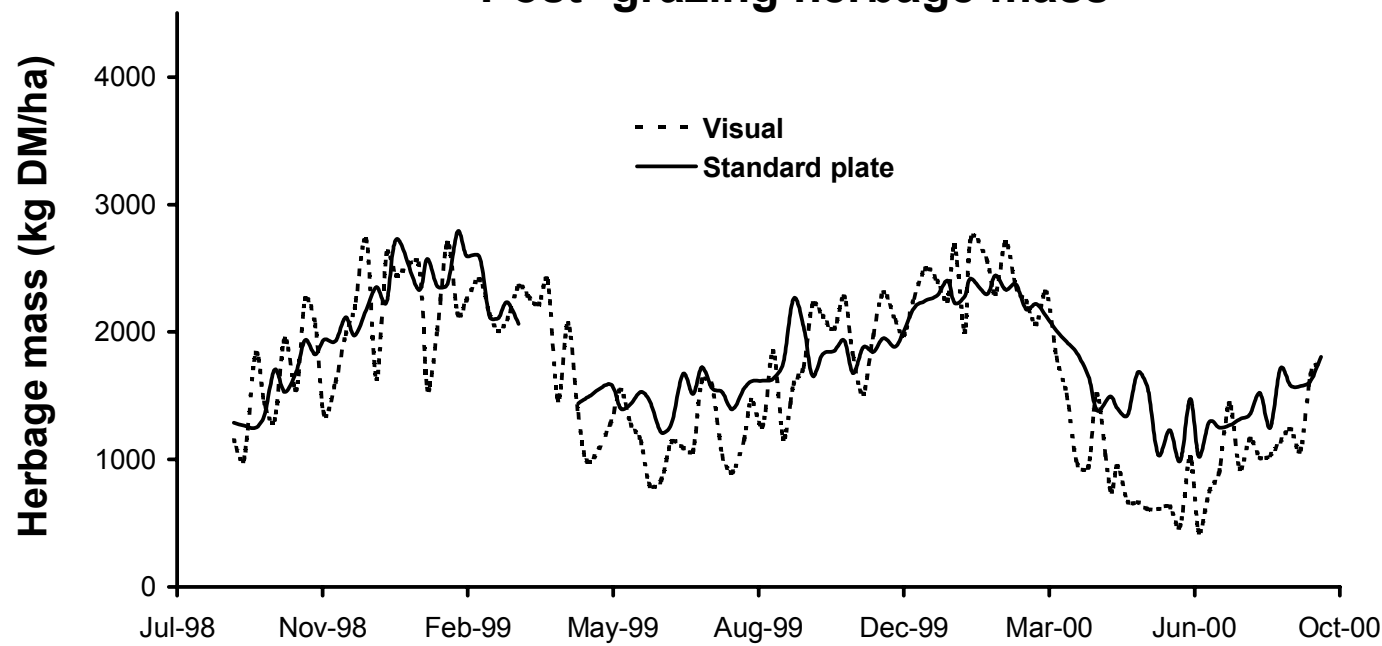

to animal performance than the No 2 RPM calibrated estimates. This finding is incongruous, because the No 2 RPM was calibrated to the same pasture as visual calibrations. Examination of the weekly calibrations showed little difference between the correlation coefficients for the No 2 RPM and the visual estimates and herbage mass. Average $\mathrm{r}^{2}$ values recorded during the 2 years for the RPM and visual estimates were 0.86 and 0.89 respectively, suggesting both methods were estimating herbage mass in the calibration quadrats with similar reliability. The assumption from this was that the RPM performs or is operated
Table 12 Average farm cover, and pre- and post-grazing herbage mass recorded during 1998-2000 at Dexcel No 2 Dairy by visual, weekly calibrated rising plate meter (RPM) and standard RPM estimates of herbage mass (kg DM/ ha).

\begin{tabular}{lccc}
\hline Estimate & Visual & No 2 RPM & $\begin{array}{c}\text { Standard } \\
\text { RPM }\end{array}$ \\
\hline Average farm cover & 2660 & 2300 & 2260 \\
Pre-grazing herbage mass & 3640 & 3000 & 3000 \\
Post-grazing herbage mass & 1650 & 1800 & 1720 \\
Difference (pre-post) & 1990 & 1200 & 1280 \\
\hline
\end{tabular}


Figure $\llbracket 4$ Comparison of the rising plate meter and the standard calibration method with visual assessment for determining average farm cover, pre- and post-grazing herbage mass at Dexcel \#2 Dairy during 1998-2000.
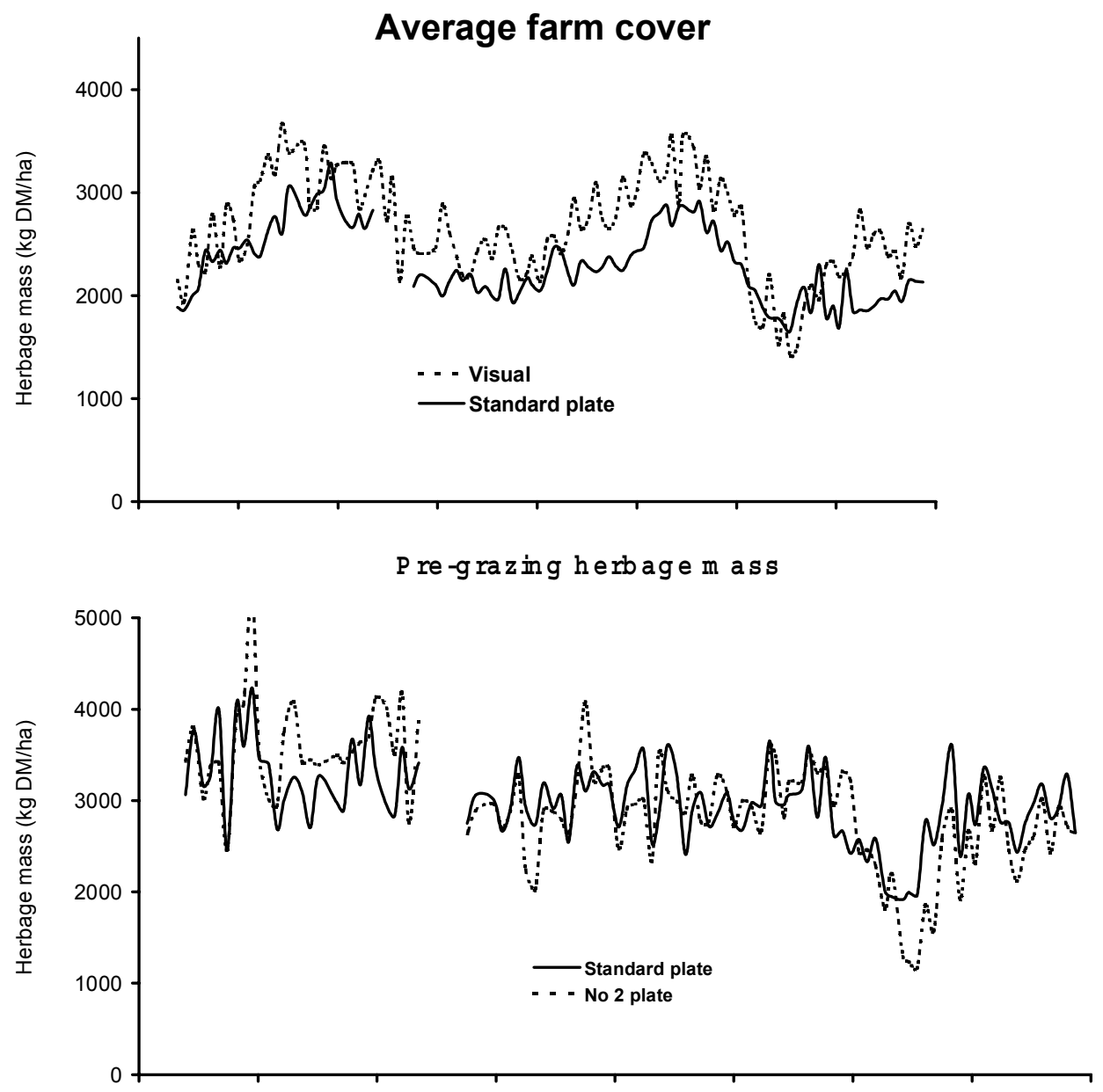

Post-grazing herbage $\mathrm{m}$ as

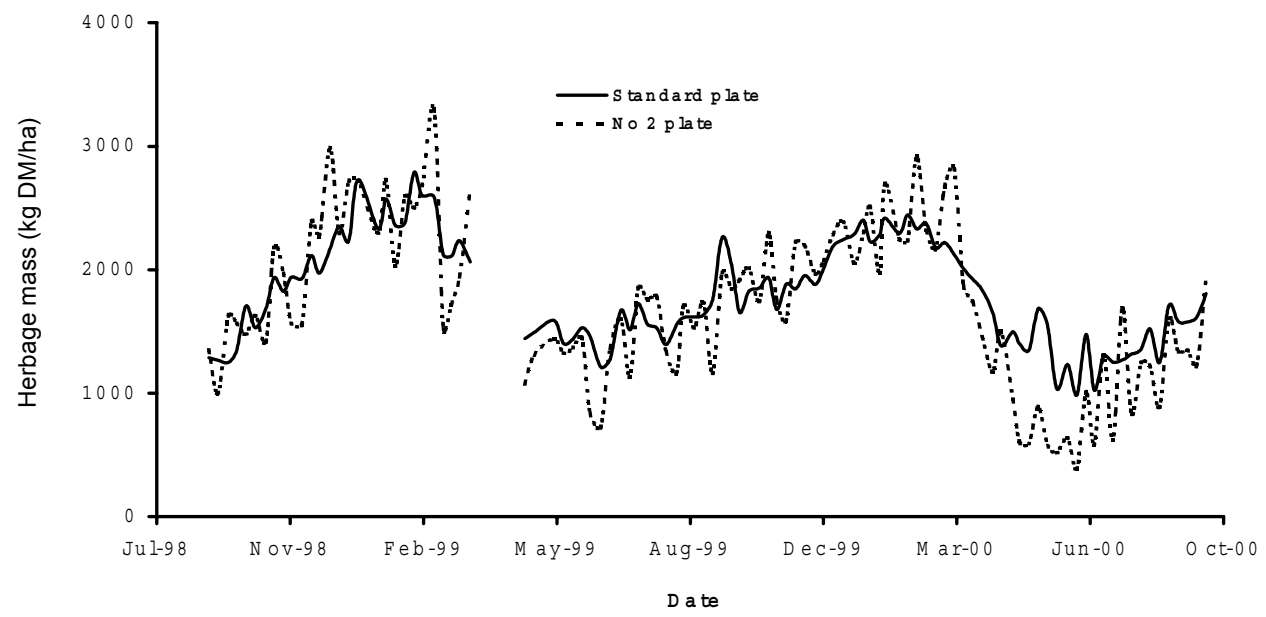


differently when taking plot measurements to when taking paddock measurements.

Davis et al. (1998) measured annual pasture production in a number of dairying districts by the "difference" method (Lynch 1966) using the RPM to assess compressed pasture height in small pasture cages and the calibrations published by L'Huillier \& Thomson (1988) to calculate herbage mass. The procedure estimated similar levels of annual pasture production to that assessed by standard visual assessment methods at WTARS and realistically predicted dairy production using the district pasture growth assessments in UDDER simulations (Davis et al. 1998). These reports suggested that when the RPM was used in calibration plots or in small pasture cages (as used in pasture growth studies), the RPM was operated differently from in the paddock. When used in small plots, the RPM was placed carefully on pasture and the only force exerted on the pasture canopy was the weight of the disk. When paddock and whole farm assessments were made, the RPM was usually placed on the pasture at an angle and with greater force, possibly compressing the height of pasture to a greater extent, causing an underestimate of herbage mass, especially in longer pasture (Figure 3).

This explanation, however, needs further testing because the method of RPM calibration used at Massey University by Bishop-Hurley et al. (1997) calibrated the average paddock RPM reading (average of 80 random RPM readings) to the average paddock herbage mass (average of five quadrats cut to ground level). No differences were found in RPM regression coefficients between the data from Massey University and the other locations, which calibrated the RPM to small quadrats.

\section{On-farm use of the standardised RPM calibrations}

The information presented does lead the authors however, to the assumption that the operation of the RPM differs between small plot and paddock measurement. This leads to a possible conclusion that the RPM, irrespective of calibration procedure, may be of limited value for assessing the range of pasture parameters considered necessary to evaluate and plan grazing management for dairying. The question is then asked, how can the RPM be used effectively with what appears a robust standard calibration method?

The assumption has been made that the RPM can estimate the herbage mass in small plots to similar values and with similar accuracy as visual assessment. If this is the case, then the RPM with the standard calibrations could be used to calibrate the visual estimator by the use of the "small plot" RPM placement technique, and the farm assessed visually. This method has not been evaluated but does offer a time/efficient and possibly more accurate method of pasture assessment than using the RPM for farm assessment. An evaluation of such a method needs to be undertaken. The calibrations reported in this paper might also be useful for the preparation of target average farm covers and post-grazing herbage mass levels that will aid grazing management practices. These targets will be comparable between farms and between regions and will greatly assist in the extension of successful grazing management practices. For the assessment of pasture production on individual farms, the technique used by Davis et al. (1998) and the standard RPM calibrations will provide a reliable method for determining pasture growth patterns and annual pasture production at low cost.

\section{Conclusion}

- No differences in the estimation of average farm cover, pre-grazing herbage mass, post-grazing herbage mass and consumed DM (pre- minus postgrazing) were found whether assessed by the RPM using a standard or an actual calibration determined for the local pasture conditions on the day of assessment.

- When compared with visually assessed values for herbage mass, the RPM assessments compared favorably for post-grazing herbage mass but gave lower estimations of pre-grazing herbage mass, average farm cover and consumed DM. It was concluded that the RPM was operated differently when taking calibration plot readings and paddock readings. This however should not preclude the RPM from pasture assessment and a method was proposed using the standardised RPM calibrations to calibrate the estimator prior to visually undertaking whole-farm herbage mass assessments.

- The standardised RPM calibrations presented apply to dairy farms dominant in ryegrass-white clover in environments where low summer rainfall limits pasture and dairy production.

- For irrigated pasture and pasture in high rainfall areas the RPM calibrations will be appropriate except during late-spring-summer when pasture conditions are quite different to those encountered in the districts from which the calibrations were derived.

More widespread adoption of the standard relationships will lead to greater standardisation of pasture assessment and increase the confidence of 
farmers in the use of the RPM to estimate pasture mass on dairy farms. The result of this will be better pasture management decisions and improved utilisation of pasture for milksolids production.

\section{ACKNOWLEDGEMENTS}

Staff who assisted on the research stations and University Farms with cutting and washing the thousands of pasture samples. Staff at Dexcel No 2 Dairy for the RPM and visual estimates used to evaluate the standard RPM calibration. Harold Henderson and Barbara Dow who assisted in the processing and interpreting the comparative data made available from Dexcel No 2 Dairy.

\section{REFERENCES}

Bishop-Hurley, G.J.; Matthews, P.N.P.; Hodgson, J.; Drake, C.; Matthew, C. 1997. Dairy systems study of the effects of contrasting spring grazing managements on pasture and animal production. Proceedings of the New Zealand Grassland Association 59: 209-214.

Davis, K.L.; Thomson, N.A.; McLean, N.R.; McCallum, D.A.; Hainsworth, R.J.; Wards, A.J.; Barton, R.G. 1998. Pasture growth on dairy farms in the Golden Bay and West Coast of the South Island. Proceedings of the New Zealand Grassland Association 60: 9-14.

Larcombe, M.T. 1989. The effects of manipulating reproduction on the productivity and profitably of dairy herds which graze pasture. PhD thesis, Melbourne University.
L'Huillier, P.J.; Thomson, N.A. 1988. Estimation of herbage mass in ryegrass-white clover dairy pastures. Proceedings of the New Zealand Grassland Association 49: 117-122.

Lile, J.A.; Blackwell, M.B.; Thomson, N.A.; Penno, J.W.; Macdonald, K.A.; Nicholas, P.K.; Lancaster, J.A.S. 2001. Practical use of the rising plate meter (RPM) on New Zealand dairy farms. Proceedings of the New Zealand Grassland Association 63: 159-164.

Macdonald, K.; Penno, J.; Nicholas, P.; Lile, J.; Coulter, M.; Lancaster J. 2001. Farm systems - Impact of stocking rate on dairy farm efficiency. Proceedings of the New Zealand Grassland Association 63: 223-227.

Upsdell M.P. 1994: Bayesian smoothers as an extension of non-linear regression. New Zealand Statistician 29: $66-81$

Stockdale, C.R. 1984. Evaluation of techniques for estimating the yield of irrigated pasture intensively grazed by dairy cows 2 . The rising plate meter. Australian Journal of Experimental Agriculture and Animal Husbandry 24: 305-311.

Thomson, N.A.; McCallum, D.A.; Howse, Holmes, C.W.; Matthews, P.N.P.; Matthew, C. 1997. Estimation of dairy pasture - the need for standardisation. Proceedings of the New Zealand Grassland Association 59: 221-225.

Thomson, N.A.; Blackwell, M.A. 1999. A new pasture assessment model. Proceedings of the South Island Dairy Event (SIDE) 1: 60-67.

Thomson, N.A. 1985. Techniques available for assessing pasture. Proceedings of the Massey Dairy Farmers' Conference 37: 113-121. 